\title{
Use of the virtual slide and the dynamic real-time telepathology systems for a consultation and the frozen section intra-operative diagnosis in thoracic/pulmonary pathology
}

\author{
Janina Słodkowska ${ }^{1,2}$, Juliusz Pankowski ${ }^{3}$, Krystyna Siemiątkowska ${ }^{4}$, \\ Lech Chyczewski ${ }^{5}$
}

${ }^{1}$ Military Institute of the Medicine, Department of Pathology, Warsaw, Poland

${ }^{2}$ Institute of Tuberculosis and Lung Diseases, Warsaw, Poland

3Pulmonary Hospital, Department of Pathology, Zakopane, Poland

${ }^{4}$ Kujawsko-Pomorskie Centre of Pulmonology, Bydgoszcz, Poland

${ }^{5}$ Medical University of Bialystok, Department of Clinical Molecular Biology, Bialystok, Poland.

\begin{abstract}
We report the results of a study designed for assessment of the diagnostic accuracy and usability of internet-based digital microscopy: the dynamic real-time telepathology system (Coolscope) and the Virtual microscopy (Aperio Scan Scope) system, in the context of pulmonary pathology. The systems were implemented to the routine pulmonary pathology workflows and used for the intra-operative frozen-section primary diagnosis as well as for the secondary (consultative) diagnosis. The histological material presented for the teleconsultations included the samples of lung parenchyma, bronchial biopsy and resected lung/bronchi tumours. For the primary diagnosis 4 categories of material can be distinguished (304 samples): 1) the frozen sections of lung tumours, resected bronchial margins and lymph nodes; 2) fine needle aspiration [FNA] biopsies (TBNA; EBUS-TBNA, EUS-FNA; 3) oligobiopses of bronchus, oesophagus, skin; and 4) exfoliative cytology. The telepathology diagnoses compared with conventional light microscopy diagnoses showed very high concordance for the Coolscope and Aperio Virtual Slide modality: $87.5 \%$ and 100\%, respectively - within the group of teleconsultations. For the frozen sections, the primary telediagnoses were concordant with the light microscopy paraffin sections diagnoses in $100 \%$ for Aperio; and in $97.5 \%$ for Coolscope. An excellent agreement $(100 \%)$ was seen in the telediagnoses and conventional slides diagnoses for FNA, oligobiopsies and cytology - for both telepathology systems. These results provide some encouragement for the implementation of Coolscope and virtual slide-based telepathology (Aperio) system to the routine histopathological diagnostics.
\end{abstract}

Key words: telepathology, pulmonary pathology, dynamic real-time telepathology, Coolscope, Aperio system, virtual slide, frozen section diagnosis, teleconsultation.

\section{Introduction}

The Polish pathology entered a new era of the digital microscopy by introduction of the digital telemicroscopes such as Nikon Coolscope and the virtual microscopy systems, to the routine diagnostic service and education [1-5]. The real-time telepathology method has proved its higher diagnostic accuracy than

Correspondence: J. Słodkowska, Military Institute of Medicine, Dept. of Pathology, Szaserów 128 str. 00909 Warsaw, Poland; tel./fax.: (+4822) 8103892, e-mail: joanslo@wp.pl static imagery and is widely used for the quick frozen section diagnosis and teleconsultation. Currently, the practical application of the virtual slide or virtual microscopy systems is seen not only in the field of education, conferences or consultations. The great technological progress brought to the telepathology [TP] modern scanners sufficient for the quick intraoperative diagnosis $[2,3,6]$.

We present the experiences of two Polish telepathology networks represented by the medical centres involved in the thoracic/pulmonary diagnostics. Two types of TP systems have been used for the intra-opera- 
Table 1. The histological material presented for TP consultations with Coolscope.

\begin{tabular}{|c|c|c|c|}
\hline No & Referring diagnosis & No of cases & Labelling of the glass slide \\
\hline I. & DILD & & \\
\hline 1. & $\begin{array}{l}\text { Granulomatous inflammatory } \\
\text { diseases: } \\
\text { EAA } \\
\text { TB } \\
\text { Sarcoidosis } \\
\text { Aspergillosis }\end{array}$ & $\begin{array}{l}5 \\
2 \\
3 \\
2\end{array}$ & $\begin{array}{l}4143 / 04 ; 4391 / 05 ; 4504 / 04 ; 8319 / 03 ; 285719 \\
5559 / 04 ; 5630 / 05 \\
1049 / 04 ; 9313 / 04 ; 5206 / 05 \\
4620 / 04 ; 197913 / 04\end{array}$ \\
\hline 2. & Pneumoconioses & 5 & $2133 / 04 ; 1388 / 05 ; 9194 / 04 ; 4044 / 04 ; 5491 \mathrm{~B} / 05$ \\
\hline 3. & $\begin{array}{l}\text { Interstitial Pneumonias [IP] } \\
\text { Usual IP [UIP] } \\
\text { UIP + Non Specific IP [NSIP] } \\
\text { UIP vs NSIP } \\
\text { NSIP } \\
\text { Organising Pneumonia [OP] } \\
\text { Lymphocytic IP [LIP] } \\
\text { Desquamative IP [DIP] }\end{array}$ & $\begin{array}{l}7 \\
2 \\
2 \\
3 \\
5 \\
1 \\
1\end{array}$ & $\begin{array}{l}609 / 04 ; 1030 / 04 ; 5989 \mathrm{~B} / 04 ; 4537 / 05 ; 10979 / 02 ; 1088 \mathrm{~B} / 04 ; 2753 / 01 \\
3534-5 / 03 ; 9286-7 / 02 \\
3735 / 04 ; 3523 / 04 \\
3045 / 05 ; 3326 / 05 ; 295957 / 99 \\
5133 / 05 ; 7105 \mathrm{~B} / 04 ; 7621 / 04 ; 288316 ; 5265 / 05 \\
296513 / 99 \\
2607 / 01\end{array}$ \\
\hline 4. & $\begin{array}{l}\text { Neoplasms } \\
\text { Hodgkin's lymphoma [HI.] } \\
\text { I.YG } \\
\text { B-cell lymphoma } \\
\text { BAC }\end{array}$ & $\begin{array}{l}1 \\
1 \\
1 \\
1\end{array}$ & $\begin{array}{l}8102 / 04 \\
2194 / 02 \\
4686 / 05 \\
8437 \mathrm{~B} / 04\end{array}$ \\
\hline 5. & Other Interstitial Diseases & 3 & $291777 ; 2030 / 05 ; \quad 3561 / 05$ \\
\hline 6. & $\begin{array}{l}\text { Other leasions } \\
\text { Hamartoma }\end{array}$ & 1 & $5390 / 05$ \\
\hline & Total & 46 & \\
\hline II. & Lung/air ways tumours & & \\
\hline & $\begin{array}{l}\text { Squamous cell ca } \\
\text { Large cell ca } \\
\text { Macrocellular ca } \\
\text { Mucoepidermoid ca } \\
\text { Carcinoid typical } \\
\text { Cystic adenoid ca } \\
\text { Fibrosarcoma? }\end{array}$ & $\begin{array}{l}7 \\
1 \\
2 \\
1 \\
1 \\
1 \\
1\end{array}$ & $\begin{array}{l}6593 / 04 ; 3309 / 04 ; 1405 / 04 ; 2281 / 04 ; 539 \mathrm{~B} / 04 ; 894 / 04 ; 5810 / 04 ; \\
6347 / 04 \text { poorly diff. } \Lambda \mathrm{D} \\
6801 \mathrm{~B} / 04 ; \quad 3850 / 04 \text { undiff ca, histiocytic lymph } \\
1582 / 04 \text { mucoepidermoid ca } \\
5816 \mathrm{~A} \text { Carcinoid typical } \\
5223 \mathrm{~B} / \text { Cystic adenoid ca } \\
2946 / 04 \text { fibroneurosa }\end{array}$ \\
\hline III. & Mediastinal Tumours & & \\
\hline & $\begin{array}{l}\text { Mature teratoma } \\
\text { Metaplastic thymoma }\end{array}$ & $\begin{array}{l}1 \\
1\end{array}$ & $\begin{array}{l}3051 \mathrm{~A} / 04 \quad \text { teratoma } \\
5245 \mathrm{~B} / 04 \quad \text { Metaplastic thymoma }\end{array}$ \\
\hline & Total & 16 & \\
\hline
\end{tabular}

Legend: EAA - Extrinsic Allergic Alveolitis; LYG - Lymphomatoid granulomatosis; BAC - Bronchiolo-Alveolar Carcinoma; ca - carcinoma.

tive frozen section - primary diagnosis and for the secondary diagnoses (consultation) in thoracic/pulmonary difficult cases, implemented to the routine workflows of the histopathology labs. The study was performed to compare the diagnostic accuracy of the internet-based telepathology systems (Coolscope - the real time dynamic TP, and Aperio - the virtual microscopy system) with conventional light microscopy, in the context of pulmonary pathology $[2,3]$.

\section{Material and methods}

Telepathology for the secondary diagnosis. The referring TP centres were located at *the Pathology Department of the KujawskoPomorskie Centre of Pulmonology in Bydgoszcz [KPCP], and at *the Department of Clinical Molecular Biology of the Medical University of Bialystok [MUB]. The consultation station worked at the Dept. of Telepathology at the Institute of TB and Lung Diseases in Warsaw [ITBLD] which is the state referral centre for the diagnostics and therapy of the interstitial lung diseases (Fig. 1). The pulmonary pathology samples represented two basic categories of 
Table 2. The groups of the histological/cytological material presented for the primary telediagnosis by Coolscope and Aperio system.

\begin{tabular}{|c|c|c|c|}
\hline Matcrial/lools & Number of cases & Coolscope & Apcrio-ImageScope \\
\hline $\begin{array}{l}\text { lirozen sections } \\
\text { I ung tumours } \\
\text { Bronchial margins } \\
\text { Lymph nodes } \\
\text { Other tissues }\end{array}$ & $\begin{array}{r}114 \\
62 \\
32 \\
16 \\
4\end{array}$ & $\begin{array}{r}81 \\
49 \\
22 \\
8 \\
2\end{array}$ & $\begin{array}{r}33 \\
13 \\
10 \\
8 \\
2\end{array}$ \\
\hline $\begin{array}{l}\text { FNA } \\
\text { Transthoracal } \\
\text { Ibna+cbus-tbna+cus-ina } \\
\text { Metastases extrapulmonary }\end{array}$ & $\begin{array}{r}174 \\
53 \\
112 \\
9\end{array}$ & $\begin{array}{r}146 \\
35 \\
103 \\
8\end{array}$ & $\begin{array}{r}28 \\
18 \\
9 \\
1\end{array}$ \\
\hline $\begin{array}{l}\text { Oligobiopsy } \\
\text { Bronchus } \\
\text { Oesophagus } \\
\text { Skin }\end{array}$ & $\begin{array}{r}13 \\
10 \\
2 \\
1\end{array}$ & $\begin{array}{r}13 \\
10 \\
2 \\
1\end{array}$ & \\
\hline Lxfoliative cylology & 3 & 3 & \\
\hline Total & 304 & & \\
\hline
\end{tabular}

Legend: FNA - Fine Needle Aspiration biopsy; TBNA - conventional transbronchial needle aspiration biopsy; TBNA+EBUS - Endobronchial ultrasound guided transbronchial needle aspiration biopsy; EUS-FNA - trans-esophageal endoscopic ultrasound scanning combined with fine needle aspiration biopsy.

the diseases: *non-neoplastic diseases (open lung biopsy and/or mediastinoscopy material) - in majority the diffuse interstitial lung diseases [DILD], and *lung tumours (bronchoscopic and mediastinoscopic biopsy, resected tumours).

Telepathology tools:

a) Coolscope (Nikon, Japan) was connected to the KPCP network $(10 \mathrm{Mb} / \mathrm{s}$ network transfer capacity) and was controlled by the remote user over Coolscope interface at ITBLD $(2 \mathrm{Mb} / \mathrm{s})$. Images were presented as live video via the Internet. Access to the Coolscope was limited to the users knowing PC address. 62 cases were consulted by Coolscope and 20 with Aperio system.

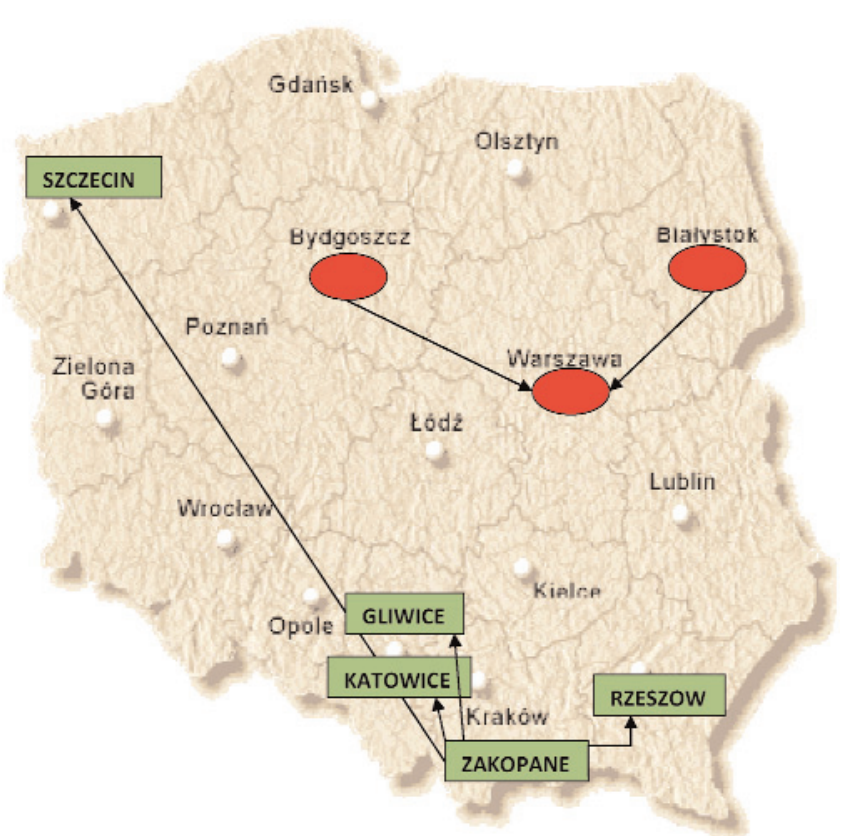

Fig. 1. The Poland territory with marks (oval and square) illustrating two telepathology networks represented by the name of cities where the consultation centres were located.
The material presented for the teleconsultation by Coolscope is shown in Table 1 . The supplementary clinical and pathomorphological data were transferred anonymously via e-mail. For the voice communication the Skype Internet was used.

b) For the Virtual Slide method, the digital slide scanner Aperio ScanScope SC (Aperio Technologies, U.S.A.) was used. 20 lung tumours from the MUB $(100 \mathrm{Mb} / \mathrm{s}$ capacity) were scanned manually under $10 \mathrm{x}$ and/or $20 \mathrm{x}$ magnification. The Virtual Slides were available on the server for teleconsultation. The collection of pulmonary tumour/tumour-like cases comprised 8 neoplastic/preneoplastic lesions with neuroendocrine [NE] differentiation, a few rare lung neoplasms and the benign tumour-like lesions.

The usefulness of the telepathology diagnosis was estimated in terms of time required, images/Virtual Slides quality and of the diagnosis accuracy. The telepathology/VS diagnoses were compared to those prepared with the conventional microscopes.

Telepathology for the primary diagnosis. The referring TP centre was located at the Pathology Lab. of the Pulmonary Hospital in Zakopane, which is the referral regional centre for the minimal invasive diagnostics of the lung cancer. There is no permanent pathologist therefore the specialised technicians processed the diagnostic material, screened it and presented for TP opinion. Material selected for the primary TP-diagnosis comprised 304 samples: frozen sections -114 , fine needle aspiration -174 , oligobiopsies -13 and exfoliative cytology -3 . The detailed list of the cases is shown in Table 2.

Telepathology tools. Coolscope (Nikon, Japan) and Aperio ScanScope SC (Aperio Technologies, U.S.A.) were connected to the telecommunication network $(256-512 \mathrm{~kb} / \mathrm{s})$ in Zakopane. The collaborating TP consultation workstations were located at: *the Lab. of Histopathology in Szczecin (band $4 \mathrm{Mb} / \mathrm{s}$ ); *the Centre of Oncology Maria Skłodowska-Curie Memorial Institute Branch in Gliwice (Dept. of Tumor Pathology); *the Hospital of TB and Pulmonary Diseases in Rzeszów (the Patomorphology Dept.) and at *the Medical University of Silesia (the Patomorphology Dept.) in Katowice (Fig. 1). The images were presented as live video via the Internet. The consultants could contribute to the TP sessions with 
Coolscope and/or Aperio only via special login. Case descriptions faxed/mailed prior to the teleconference identified the diagnostic needs. Pathology images/VS were displayed for the final decisions by a consensus-based approach. The telepathology/VS diagnosis was verified by the light microscopy examination of the paraffin sections.

\section{Results}

The main diagnostic difficulties referred to the examined cases included: microscopic classification of the idiopathic Interstitial Pneumonias [IP] (Usual IP vs Non-Specific IP [NSIP]; mixed multilobular pattern of UIP+NSIP; honeycombing stage of IP); differential diagnostics for the granulomatous inflammatory reaction in chronic Extrinsic Allergic Alveolitis [EAA], atypical sarcoidosis, chronic Aspergillosis; differentiation of the fibrotic nodular lesions related to the occupational exposure; lymphoproliferative and lymphoid neoplastic lesions. All these diagnostic problems were solved by the teleconsultations except of 5 cases for which only "working" (descriptive, differential) TPdiagnoses were proposed. These cases needed supplementary immunohistochemical staining (for lymphomas); or the special staining and a review of occupational history of the patient (EAA, fungal infection). All TP-diagnoses were concordant with the referral diagnoses in their main categories. There was no disagreement in any of the TP-diagnosis and light microscopy results of the reviewer.

In relation to the lung tumours consulted by Coolscope, the referring and TP-diagnoses were concordant in $90 \%$ (18 out of 20); 2 cases needed further immunohistochemical staining (macrocellular carcinoma and secondary pulmonary sarcoma). However a complete agreement was achieved in all TP-diagnoses and light microscopy opinions.

Telepathology examination and diagnosis of the viewer were achieved within range of 4 to $30 \mathrm{~min}$. All transmissions of the digital images were successful with very rapid downloading ( $<30 \mathrm{sec}$.) confirming sufficiency of the Internet communication.

By implementation of the Virtual Slide method with Aperio system we dealt with huge files up to $400 \mathrm{MB}$ for a single slide of resected tumour. The time required for making up a VS file ranged between 2-7 min. for the manual focusing and scanning. All VS showed excellent quality. The average time needed for full examination of VS varied between cases but didn't overcome 20 minutes. There was $100 \%$ concordance between the TPdiagnosis and parallel conventional original diagnosis of the viewer. Discordant opinions were presented by the referring and consulting pathologists in one case but this disagreement was related to the histopathological difficulties not to the TP technology. The Virtual Slide method was successfully used for the teleconsultations of the pulmonary oncology cases.
The Pulmonary Hospital in Zakopane is a regional referral centre for the following diagnostic modalities: standard diagnostics and surgery of lung cancer, endobronchial ultrasound-guided transbronchial needle aspiration (EBUS-TBNA) and trans-esophageal endoscopic ultrasound scanning (EUS) combined with fine needle aspiration (EUS-FNA) or transcutaneous (transthoracic) FNA biopsy under real-time ultrasound or Rtg-scopy guidance. These procedures were indicated for the patients with unknown primary mediastinal lesions, mediastinal adenopathy caused by the diseases involving lymph nodes of the mediastinum e.g.: TB, sarcoidosis or metastases from a range of cancers, and as the staging modality for lung cancer $[7,8]$.

The prospective analysis of 304 histological materials underwent quick remote diagnostics to obtain a primary telediagnosis (Table 2). The performed telediagnostics comprised 248 sessions with Coolscope and 56 by Aperio system. The TP-diagnosis based on a consensus of 4 experts remote opinions was reviewed by the light microscope examination of the paraffin sections by each viewer. For the VS-diagnosis of 33 frozen sections there was $100 \%$ concordance with the conventional microscopy diagnoses; for 81 telediagnoses by Coolscope and paraffin sections with light microscopes the concordance was $97,5 \%$. One false negative telediagnosis of the granulation was replaced by the sarcomatoid carcinoma diagnosed in the paraffin sections. One uncertain TP-diagnosis: suspicious of carcinoma within an abscess wall was changed to squamous cell carcinoma in paraffin sections diagnosis. $100 \%$ concordance was reached in the TP-diagnoses and conventional paraffin section diagnoses for 31 bronchial margins (11 positive for carcinomatous infiltration), 16 lymph nodes ( 5 cases with carcinomatous metastases) and other 2 samples of this group (Table 3).

Within the group of FNA biopsy, the concordance in the VS-diagnoses and paraffin section final diagnoses was $100 \%$ (28/28); for the Coolscope diagnoses and paraffin section diagnoses the concordance was 98,6\% (144/146). Two false positive telediagnosis: suspicious for carcinomatous cells were changed to: negative for the carcinomatous cells in light microscopy examination of the paraffin sections. 167 FNA biopsy samples were positive for the carcinoma cells: 112 - non-small cell carcinoma, 21 - small cell ca, 21 - squamous cell ca and 14 - adenocarcinoma.

The oligobiopsies showed the carcinomatous cells in 11 out of 13 samples: 6 - squamous cell ca, 2 small cell ca, 2 - non-small cell ca, 1- basal cell ca (skin biopsy). There was 100\% concordance in TPdiagnoses (obtained by both TP-methods) with the paraffin section diagnoses. Also for the cytological material 3/3 TP-diagnoses by Coolscope were concor- 
Table 3. Comparison of the frozen section telediagnoses with the paraffin section final diagnoses.

\begin{tabular}{|c|c|c|c|c|}
\hline $\begin{array}{l}\text { Histological samples } \\
\text { (n) }\end{array}$ & $\begin{array}{l}\text { Consensus telediagnosis } \\
\text { (n) }\end{array}$ & $\begin{array}{l}\text { Dgn by light microscope } \\
\text { (n) }\end{array}$ & $\begin{array}{l}\text { Uncertain } \\
\text { telediagnosis } \\
\text { (n) }\end{array}$ & $\begin{array}{l}\text { lalse negative } \\
\text { telediagnosis } \\
\text { (n) }\end{array}$ \\
\hline Lung tumours (42) & $\begin{array}{l}\text { n-micorcellular ca (32) } \\
\text { sqc (7) } \\
\text { ad (3) } \\
\text { malignant neoplasm (1) }\end{array}$ & $\begin{array}{l}\text { n-micorcellular ca (32) } \\
\text { sqc (7) } \\
\text { ad (3) } \\
\text { malignant neoplasm (1) }\end{array}$ & & \\
\hline Lung tumour (1) & & sqc (1) & $\begin{array}{l}\text { susp. of ca in abscess (1) } \\
\text { (Coolscope) }\end{array}$ & \\
\hline I ung tumour (1) & $\begin{array}{l}\text { granulation (1) } \\
\text { (Coolscope) }\end{array}$ & sarcomatoid ca (funal cavity) (1) & & granulation (1) \\
\hline Lung tumour (1) & $\begin{array}{l}\text { descriptive non } \\
\text { conclusive dgn(1) }\end{array}$ & descriptive non conclusive dgn( 1 ) & & \\
\hline Bronchial lesions (16) & $\begin{array}{l}\text { hamartoma (4) } \\
\text { tb (2) } \\
\text { inflammation (4) } \\
\text { undefined (6) }\end{array}$ & $\begin{array}{l}\text { hamartoma (4) } \\
\text { tb (2) } \\
\text { inflammation (4) } \\
\text { undefined (6) }\end{array}$ & & \\
\hline Bronchial margine (33) & $\begin{array}{l}\text { ca infiltration (11) } \\
\text { free margin (21) }\end{array}$ & $\begin{array}{l}\text { ca infiltration (11) } \\
\text { free margin (21) }\end{array}$ & & \\
\hline $\begin{array}{l}\text { Lymph Nodes } \\
\text { (usually N2) (11) }\end{array}$ & $\begin{array}{l}\text { ca metastases (5) } \\
\text { free of ca (11) }\end{array}$ & $\begin{array}{l}\text { ca metastases (5) } \\
\text { free of ca (11) }\end{array}$ & & \\
\hline Others (2) & no carcinomatous cells (2) & no carcinomatous cells (2) & & \\
\hline
\end{tabular}

dant with the paraffin section diagnoses (one was positive for the carcinomatous cells).

\section{Discussion}

Among the pulmonary pathology cases presented for TP consultations dominated the Diffuse Interstitial Lung Diseases which are characterised by various clinical, radiological and histological manifestations. They affect manly the lung interstitium but also other anatomic aspects of the lung structure, therefore they may present a complex morphology and can be a diagnostic problem for the pathologist. Our previous study documented that the static telepathology method is an inappropriate one for the DILD teleconsultation [9]. High quality of the digital images produced by Coolscope has facilitated the microscopic evaluation and the differential diagnoses of all DILD cases. Application of the digital telemicroscopy system - Coolscope to the teleconsultations of the pulmonary pathology cases confirmed very high diagnostic accuracy of TP-diagnoses in DILD and lung tumours. The VS telepathology system and Coolscope were found to be superior to the conventional still-image system in terms of time required for diagnosis and of ease and accuracy of the diagnosis in DILD. These observations are in agreement with other published opinions referred to various branches of diagnostic pathology $[3,10]$. The VS telepathology diagnosis was easier and more comfortable due to greater image information than static TP or dynamic real time TP.

The frozen section intra-operative material as well as the tiny TBNA or FNA biopsies (obtained in any of above used diagnostic procedures) is a great diagnostic challenge for the pathologist. A chance for the supporting second opinion (consultation/teleconsultation) is very important for the pathologist and beneficial for the patient. The results of our study confirm the successful supportive contribution of the internet-based telepathology systems in the quick and accurate frozen intra-operative diagnosis as well as in the paraffin section second opinion.

The study has been unable to detect any significant difference between accuracy of diagnoses made by internet-based telepathology and those made by conventional light microscopy, in context to any material used in pulmonary pathology service. Our results indicate that the time needed by the pathologist for VS examination is longer than for the conventional microscopy investigation. We conclude that dynamic real-time TP (Coolscope) can be alternative method for the consultation of DILD and lung tumours. Accessibility of web-based Virtual Slides and access to Coolscope via Internet allow many pathologists contribute in teleconsultation which can improve the diagnostic accuracy. Both TP tools used for remote internet-based consultations were sufficient for the diagnosis and confirmation of the malignant lesions in the respiratory system. The percentage of concordant 
results for the remote frozen section diagnosis is comparable with the concordance rate of the light microscopy diagnosis in the paraffin thoracosurgical material. The limitation for the Coolscope application is insufficient telecommunication bands (it is much easier to confirm the presence of carcinomatous cells than to proof that they are not present). Very high $(100 \%)$ concordance in the distant and light microscopy diagnoses for the bronchial margins in frozen sections has confirmed the professional contribution of the technicians selecting the fields for $\mathrm{TP} /$ microscopic evaluation.

Acknowledgements: With the assistance of the following consultant pathologists: Professor D. Lange, Dr B. Maksymiuk from the Centre of Oncology Maria Skłodowska-Curie Memorial Institute Branch in Gliwice; Dr E. Kaznowska from the Hospital of TB and Pulmonary Diseases in Rzeszów; Dr W. Zajęcki from the Medical University of Silesia - in Poland. This paper has been partly supported by the COST Action IC0604.

\section{References}

[1] Coolscope [http://www.coolscope.com]

[2] Aperio [http://www.aperio.com]
[3] Tsuchihashi Y, Takamatsu T, Hashimoto Y et al. Use of virtual slide system for quick frozen intra-operative telepathology diagnosis in Kyoto, Japan. Diagn Pathol. 2008;3(Suppl 1):S6.

[4] Banach L, Stepien A, Schneider J, Wichrzycka-Lancaster E. Dynamic active telepathology over National Health Laboratory service network, South Africa: feasibility study using Nikon Coolscope. Diagn Patholl 2008;3(Suppl 1):S3.

[5] Schrader T, Niepage S, Leuthold T et al. The diagnostic path, a useful visualisation tool in virtual microscopy. Diagn Pathol. 2006;1:40.

[ 6] Rojo MG, Bueno G, Slodkowska J. Review of imaging solutions for integrated quantitative Immunohistochemistry in the pathology daily practice. Folia Histochem Cytobiol. 2009; 47(3):349-354.

[ 7] Vilmann P, Puri R. The complete "medical" mediastinoscopy (EUS-FNA+ABUS-TBNA). Minerva Med. 2007;98:331338.

[ 8] Vincent BD, El-Bayoumi E, Hoffman B. et al. Real-time endobronchial ultrasound-guided transbronchial lymph node aspiration. Ann Thorac Surg. 2008;85:224-230.

[ 9] Slodkowska J, Kayser K, Kuś j, Auer I: Utility of the teleconsultations in the pulmonary pathology cases. Ann Acad Studenica. 2001;4:15-19.

[10] Furness P. A randomized controlled trial of the diagnostic accuracy of internet-based telepathology compared with conventional microscopy. Histopathology. 2007;50:266-273.

Submitted: 28 October, 2009 Accepted after reviews: 20 December, 2009 